\title{
Eastern Bloodsucking Conenose, Triatoma sanguisuga (LeConte) (Hemiptera: Reduviidae: Triatominae) ${ }^{1}$
}

\author{
John L. Capinera ${ }^{2}$
}

\section{Introduction}

The eastern bloodsucking conenose, Triatoma sanguisuga (LeConte), belongs to the subfamily Triatominae, known as the kissing bugs. Kissing bugs are members of a larger group known as assassin bugs. Assassin bugs are named for their habit of attacking and voraciously feeding on insects with their piercing-sucking mouthparts. In this way, assassin bugs can reduce pest insect populations, and are considered beneficial (Drees and Jackman 1999). Kissing bugs, despite their affectionate vernacular name, are particularly threatening "assassins" who require blood meals to survive and reproduce.

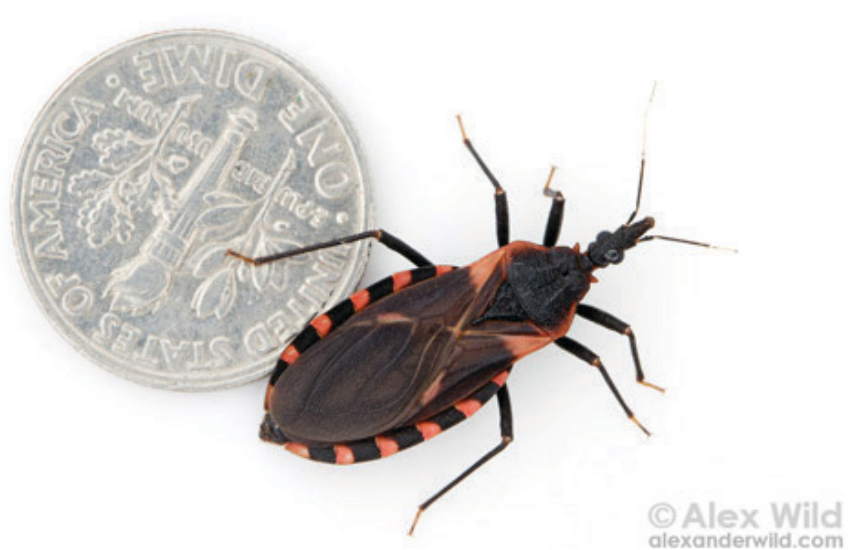

Figure 1. Triatoma sanguisuga (LeConte), the eastern bloodsucking conenose, with a dime shown for scale.

Credits: Alexander Wild, used with permission
Triatoma sanguisuga is a known vector of American trypanosomiasis (or Chagas Disease) in South America, a debilitating illness caused by the parasite Trypanosoma cruzi. This parasite has a complex life cycle, relying on both invertebrate vectors (such as the eastern bloodsucking conenose) and mammalian hosts (such as humans, livestock and rats) to reproduce and spread. This disease is a problem in South and Central America and has been detected in the United States, but has not been found in Florida.

\section{Distribution}

Triatoma sanguisuga is found throughout Latin America and in the southeastern United States ranging from Pennsylvania to Florida and west to California (Maurer 2013). The parasite Trypanosoma cruzi that causes American trypanosomiasis is especially widespread in rural Latin America, but not North America (Center for Disease Control and Prevention 2013). Even in Central and South America, Triatoma sanguisuga is not the major invertebrate vector of Trypanosoma cruzi. There the kissing bug of concern is Triatoma infestans, known as vinchuca or simply the bloodsucking conenose.

\section{Description}

\section{Eggs}

The eggs of Triatoma sanguisuga are pearly-white, oval, and approximately $1.5 \mathrm{~mm}$ long. Eggs are indiscriminately

1. This document is EENY581, one of a series of the Entomology and Nematology Department, UF/IFAS Extension. Original publication date November 2013. Visit the EDIS website at http://edis.ifas.ufl.edu.

2. John L. Capinera, professor/chairman, Entomology and Nematology Department, UF/IFAS Extension. Gainesville, FL 32611.

The Institute of Food and Agricultural Sciences (IFAS) is an Equal Opportunity Institution authorized to provide research, educational information and other services only to individuals and institutions that function with non-discrimination with respect to race, creed, color, religion, age, disability, sex, sexual orientation, marital status, national origin, political opinions or affiliations. For more information on obtaining other UF/IFAS Extension publications, contact your county's UF/IFAS Extension office. 
deposited individually on the substrate. Once a blood meal is taken, females begin oviposition after 4-6 days, depositing 1-5 eggs per day (Grundemann 1947). In a study by Hays (1965), female nymphs collected in the field that developed into adults under laboratory conditions each laid an average of 711 eggs in their lifetime. However, the range of eggs laid per female was large (from 312 to 1166) indicating a need for more research in this area.

\section{Nymphs}

According to Grundemann (1947), Triatoma sanguisuga goes through eight instars, determined by measuring the head capsule (because of the swelling associated with blood-feeding, body size is an inaccurate measurement). In a laboratory setting, each instar lasted approximately 41 days. Each molt requires blood-feeding. Development time is directly linked to temperature and host availability.

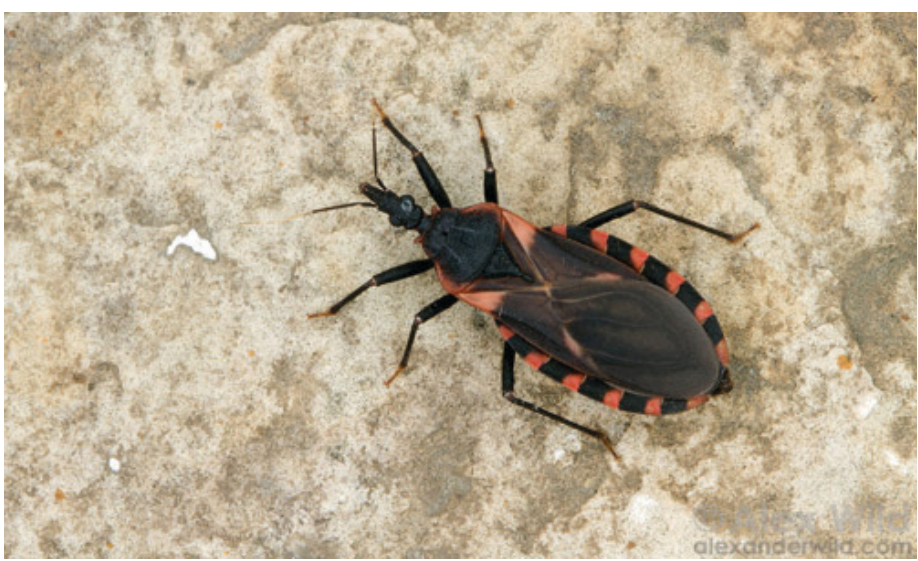

Figure 2. An adult Triatoma sanguisuga (LeConte), the eastern bloodsucking conenose.

Credits: Alexander Wild, used with permission

\section{Adults}

Triatoma sanguisuga adults are approximately $19 \mathrm{~mm}$ long, with dark brown to black, flattened bodies and elongate, cone-shaped heads (Griffith 1979). Antennae are elbowed, with six segments. The head bears a slender beak-like structure used to administer the notorious kiss, or bite. The abdomen is wide, with sides sticking out past the wing margins, displaying six reddish-orange spots on each side (Drees and Jackman 1999).

\section{Habitat}

When present in dwellings, Triatoma sanguisuga tends to hide during the day, descending at night to feed. 5I FIF insects are usually found in dark, secluded corners of homes such as cracks in the walls or ceilings. Likewise, in a natural setting they prefer a clandestine habitat, seeking refuge under leaf litter or rocks. They can be nidicolous, or prone to hiding in the nests or burrows of animals.

\section{Biology}

Kissing bugs are so named because when they descend upon sleeping humans to feed, they bite them on the face, usually near the mouth or eyes. After feeding and ingesting blood, kissing bugs typically defecate near the site of the bite. Although these bites are not particularly painful, they are irritating, and it is common for the sleeping victim to scratch or rub their face near the site of the wound. Through this scratching or rubbing, any feces deposited by the insect can enter the site of the bite (Capinera 2010). The feces of the feeding insect will contain trypanosomes if the insect is infected with Trypanosoma cruzi. Once the feces enters the bite, the wound becomes contaminated with Trypanosoma cruzi, the cause of American trypanosomiasis (or Chagas disease) in humans.

Wildlife infected with these trypanosomes are usually asymptomatic. Infected animals act as reservoirs, allowing the parasite to reproduce and providing a source from which more kissing bugs can acquire the pathogen. Humans are at risk because they often live in close contact with these mammalian hosts, which include rats, opossums and armadillos, as well as domesticated animals such as cats, dogs, guinea pigs and livestock. Rats are well established as reservoirs for many zoonotic pathogens that cause diseases such as Lyme and Plague. Rats are truly cosmopolitan, with worldwide distribution and an affinity for human food and shelter, which increases human risk of infection (Rand 2011).

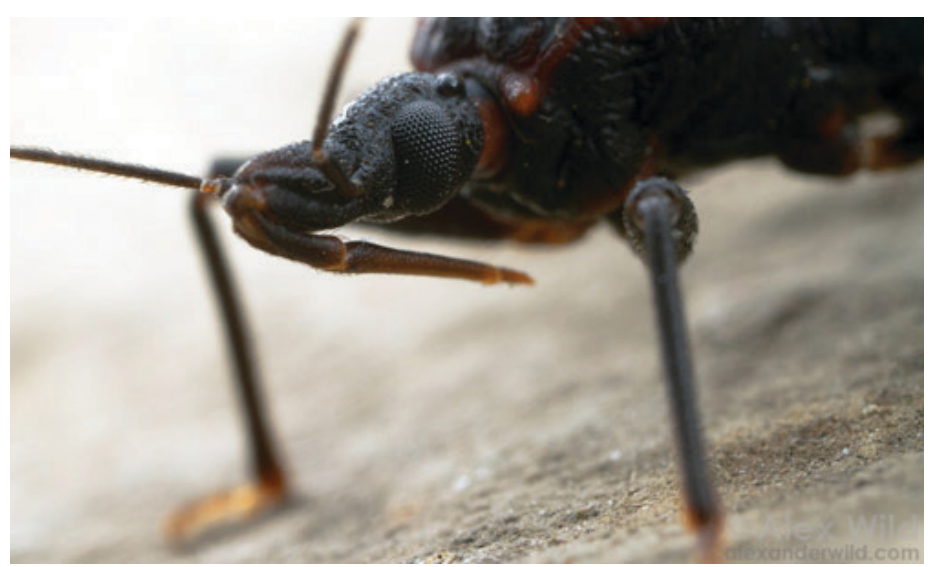

Figure 3. The head of Triatoma sanguisuga (LeConte), the eastern bloodsucking conenose, illustrating the three-segmented beak it uses to bite and draw blood from its victims.

Credits: Alexander Wild, used with permission

American trypanosomiasis (Chagas disease) is caused by the trypanosome parasite, Trypanosoma cruzi. Trypanosomes are zooflagellate protozoans that inhabit the blood. 
There are typically two phases of American trypanosomiasis. The first is an acute phase that occurs soon after infection, and includes such non-specific symptoms as fever, fatigue, headache, rash, diarrhea and vomiting. Sometimes there are no symptoms at all. Romaña's sign, a swelling of the eyelid near the site of the bite, is usually the first indication of infection (Capinera 2010, Center for Disease Control and Prevention 2013). Other signs of infection can include swelling of the liver, spleen or lymph glands. If untreated, the disease can progress into the chronic second stage, causing heart or intestinal problems, which can be fatal. In some cases, the second stage does not occur for decades after the initial infection and it may never occur.

\section{Life Cycle}

The life cycle of Triatoma sanguisuga is hemimetabolous (or "incomplete"), meaning the juvenile life stages look much like the adult stage, only smaller and lacking some features like wings. After the egg hatches, the immature bug feeds and molts eight times, taking a blood meal before each molt, before maturing into a reproductive adult (Kobylinksi and Connelly 2006). As adults, these bugs are polygynandrous, meaning each sex mates with several different individuals during their lifetime.

The female has eggs present in her ovarioles, but they are not deposited until after a male fertilizes them and she has taken a blood meal. It is possible for a female to lay hundreds of eggs in her lifetime. Research suggests that eggs are deposited at a greater volume when temperatures are warm and constant (Grundemann, 1947).

When describing the life cycle of Triatoma sanguisuga with an emphasis on its importance as a disease vector, it is important to consider the life cycle of the parasite it carries. Bern et al. 2011 gives an account of the life cycle of Trypanosoma cruzi as described in 1909 by Carlos Chagas, the discoverer of Chagas' disease. According to Bern et al., Trypanosoma cruzi is a kinetoplastid protozoan that utilizes vertebrate and invertebrate hosts in different stages of its life cycle. When a triatomine bug takes a blood meal from a vertebrate reservoir, it ingests trypomastigotes. These trypomastigotes develop into epimastigotes in the midgut of the triatomine bug. These epimastigotes move to the hindgut of the bug and form metacyclic trypomastigotes, the infective stage of the parasite that is present in the bug's feces.

When the feces enter a wound or come in contact with a mucous membrane on the mammalian host, the host can become infected. Once the trypomastigotes are present within the mammalian hosts, they differentiate into an amastigote form within the cell. These replicate quickly. From this stage, more trypomastigotes are created, which are released into the body of the mammalian hosts after the infected cell ruptures. New cells are invaded, and the cycle continues for the lifetime of the host, unless medical treatment can eradicate the parasite.

\section{Hosts}

A very important element of this disease cycle involves wildlife. Some animals act as reservoirs of Trypanosoma cruzi, allowing the disease-causing agent to multiply without affecting the animal. Because the animals do not succumb to the disease, they act as a constant source of Trypanosoma cruzi that can be easily acquired by other kissing bugs.

Early observations note Triatoma sanguisuga using rats as a natural host; the bugs benefit from hiding in the rodent burrows to feed and digest blood meals (Grundemann 1947). Other hosts in the United States include armadillos and opossums (Triplehorn and Johnson 2005). It has been recorded that cats, dogs, raccoons and livestock can carry Trypanosoma cruzi (Griffith 1947). According to Bern (2011), additional animals that have tested positive for Trypanosoma cruzi include frogs, chickens and horses.

Griffith 1947 reports that the public health considerations of Trypanosoma cruzi transmission via Triatoma sanguisuga are especially important because "such complex hostparasite relationships, involving insect and wild-animal reservoirs of disease are responsible for some of the most difficult problems in preventative medicine and public health." Due to the complex life cycle of these bugs, and their often undetected, nocturnal feeding episodes, transmission of the Trypanosoma cruzi parasite can be hard to control, manage or detect.

\section{Medical Importance}

There is a huge disparity between the American trypanosomiasis situation in North America and that of Central and South America. Although the disease has been found in North America, the situation is not nearly as devastating and serious as it is in South and Central America. According to Capinera (2010), this disease plagues roughly 15-18 million individuals in Central and South America and claims around 50,000 lives every year. The number of infected and at risk individuals is hard to estimate, considering the potential lack of symptoms in the acute phase of the disease. 
As mentioned earlier, there are many potential wildlife hosts of Trypanosoma cruzi such as rats, raccoons, opossums, cats, dogs and cattle (Bern et al. 2011). In the U.S., many of these animals have been found to harbor the parasite, making them reservoirs. This news seems concerning, since wildlife reservoirs and triatomine vectors seem to be all that is needed for the disease to spread. However, the threat of American trypanosomiasis in the U.S. is low due to two important reasons. 1) There is not a large, concentrated population of infected individuals in North America like there is in South America. 2) The triatomine vectors in the U.S. do not defecate on their hosts immediately after feeding, which is crucial for transmission of the pathogen. This is because American trypanosomiasis is not spread via the bite of a triatomine bug, but through dried Triatoma sp. feces being rubbed into a wound, orifice or mucous membrane (the eye being the most common) (Capinera 2010).

Kissing bugs are not the only cause of Trypanosoma cruzi transmission. This pathogen can be transmitted from mother to child during pregnancy or at birth. Infection can also occur through blood transfusions, organ transplant and contaminated (uncooked) food.

American trypanosomiasis is treated using a combination of two medicines. When administered in the acute phase, treatment reduces the expression or severity of the chronic phase (Cesa et al. 2011). Though seemingly promising, these medicines are not able to cure the disease completely. Also, they have many unpleasant side effects and are not approved by the FDA (Center for Disease Control 2013). For now, the best action against American trypanosomiasis is prevention.

\section{Management}

One of the best ways to control Triatoma sanguisuga in the home is by removing suitable habitat. Vacuuming, cleaning or sealing all cracks and crevices in the walls or ceilings leaves these bugs with few places to hide. One of the simplest preventative measures is to erect screens on all windows and doors, and/or to sleep beneath fine mesh netting. This is a highly effective precaution, since the bugs are nocturnal and prone to seeking hosts for a blood meal while the people are sleeping.

\section{Selected References}

Bern C, Kjos S, Yabsley MJ, Montgomery SP. 2011. Trypanosoma cruzi and Chagas disease in the United States. Clinical Microbiology Reviews. 24: 4.
Capinera JL. 2010. Insects and wildlife: arthropods and their relationships with wild vertebrate animals (1st edition), Wiley-Blackwell, Chichester, West Sussex, UK, pp. 302-303.

Center for Disease Control and Prevention. 2013. Parasites - American trypanosomiasis (also known as Chagas disease). (14 November 2013).

Cesa K, Caillouët A, Wesson DM. 2011. High Trypanosoma cruzi (Kinetoplastida: Trypanosomatidae) prevalence in Triatoma sanguisuga (Hemiptera: Reduviidae) in Southeastern Louisiana. Journal of Medical Entomology. 48: 1091-1094.

Drees BM, Jackman J. 1999. Kissing bug, conenose bug, masked hunter. Field guide to Texas insects, Gulf Publishing, Houston, Texas. (14 November 2013).

Griffith ME. 1947. The bloodsucking conenose, or "big bedbug," Triatoma sanguisuga (LeConte), in an Oklahoma City household. Proceedings of the Oklahoma Academy of Science. 28: 24-27.

Grundemann A. 1947. Studies on the biology of Triatoma sanguisuga (LeConte) in Kansas, (Reduviidae, Hemiptera). The Journal of the Kansas Entomological Society. 20:3.

Hays KL. 1965. Longevity, fecundity, and food intake of adult Triatoma sanguisuga (LeConte) (Hemiptera: Triatominae). Journal of Medical Entomology 2: 200-202.

Kobylinski K, Connelly RR. 2006. Blood feeding insect series: American trypanosomiasis - Chagas disease. Electronic Data Information Source, UF/IFAS. (no longer available online).

Lent H, Wygodzinsky P. 1979. Revision of the Tratominae (Hemiptera, Reduviidae), and their significance as vectors of Chagas' disease. Bulletin of the American Museum of Natural History. 163: 1-520.

Maurer L. 2013. Triatoma sanguisuga. Animal Diversity Web. (14 November 2013).

Rand M. 2011. Zoonotic diseases: institutional policies and procedures. Office of Research, The University of California, Santa Barbara. (14 November 2013).

Triplehorn CA, Johnson NF. 2005. Borror and Delong's introduction to the study of insects (7th edition), Brooks/ Coles, Belmont, California. p 297. 